\title{
Ressignificando o protagonismo da pessoa idosa
}

\author{
Eloá Aparecida Caliari Vahl
}

eloacv@yahoo.com.br

Cynthia Colombi Zappelini

cynthiazappelini@yahoo.com.br

\section{Resumo}

Trata-se de um relato de experiência do projeto de extensão "Ressignificando a arte do envelhecer", desenvolvido no Núcleo de Estudos da Terceira Idade da Universidade Federal de Santa Catarina, no ano de 2012. O objetivo foi atender às necessidades de integração e socialização de pessoas idosas, promovendo encontros intergeracionais, trocas de experiências e aprendizagens, ressignificando a arte do envelhecer no processo educativo, propiciando meios para construção de seres que dão significado às suas próprias histórias. A experiência foi desenvolvida utilizando a prática de animação sociocultural de Ander-Egg. Foram oferecidas aos participantes as oficinas de criatividade e visitas aos diferentes espaços de cultura e ciências da UFSC, ao longo do ano de 2012. Verificou-se que as atividades possibilitaram reforçar as relações interpessoais e, no contexto sócio cultural, oportunizar a ressignificação da autoimagem e da autoestima, estimular a memória, a comunicação, a criatividade e a integração social. Considerou-se que as experiências vivenciadas pelos participantes possibilitaram a apreensão de conteúdos e o estabelecimento de vínculos, estimulando a participação ativa no contexto institucional e comunitário, com vistas ao protagonismo da pessoa idosa.

Palavras-chave: Idoso. Protagonismo. Intergeracionalidade. Educação permanente.

\section{Resignifying the protagonism of the elderly}

\section{Abstract}

This is an experience report about the extension project "Redefining the Art of Aging" developed at the Center of Studies of the Third Age, at the Federal University of Santa Catarina, in the year 2012. The objective was to meet the needs on integration and socialization of the elderly, promoting intergenerational meetings, exchanges of experiences and learning, giving a new meaning to the art of aging in the educational process, providing means to the construction of human beings that give meaning to their own stories. This research was conducted by using the practice of socio-cultural animation by Andre Egg. It was possible to offer creativity workshops to the participants and visits to different scientific and cultural areas at UFSC, throughout the year 2012. It was found that the activities allowed strengthening the interpersonal 
relationships and socio-cultural context nurturing the

redefinition of self-image and self-esteem, stimulating the memory, communication, creativity and social integration. It was considered that the participants' experiences permitted to acquire contents and create links, and encouraged the active participation in the institutional and community contexts in relation to the elderly's protagonism.

Key words: Elderly. Protagonism. Intergenerationality. Continuing education.

\section{INTRODUÇÃO}

A Organização Mundial da Saúde vem chamando a atenção de todos para o aumento gradual da população idosa no mundo, a cada ano que passa. Segundo dados do IBGE (2010), a população com mais de 60 anos representa atualmente quase $12 \%$ dos brasileiros.

O projeto "Ressignificando a arte do envelhecer" acontece no Núcleo de Estudos da Terceira Idade da Universidade Federal de Santa Catarina (NETI/UFSC) desde 2010, visando atender a necessidade de integração e socialização de seus participantes, através de atividades artístico-culturais, promovendo encontros intergeracionais, trocas de experiências e aprendizagens, e, sobretudo, oferecendo “[...] não apenas o convívio entre as gerações, mas também de criação de inúmeras formas de relacionamentos [...] desenvolvendo o respeito mútuo e o estabelecimento de igualdade para todos" (LIMA, 2008, p.186).

Em 2012, o projeto teve como objetivo integrar as diversas atividades oferecidas pelo NETI, ressignificando a arte do envelhecer no processo educativo e desenvolvendo, valorizando e potencializando o ser idoso. Apresenta-se aqui o relato de experiência dos trabalhos desenvolvidos em 2012, descrito em dois momentos de ressignificação e integração dos participantes idosos. As ações possibilitaram a construção coletiva de um novo significado de convivência, interação e estímulo do potencial criativo individual e coletivo, favorecendo o crescimento pessoal e incentivando a participação social da pessoa idosa, com vista à visibilidade de uma imagem construtiva do envelhecer.

\section{0 relato da experiência}

O projeto embasou-se na prática de animação sócio-cultural de Ander-Egg (2000), que tem como princípios favorecer a participação, viver em relação, respeito e aceitação, dando a oportunidade de trocar ideias e contribuir para a livre expressão, promovendo a igualdade de oportunidades, diminuindo o vazio sociocultural entre as camadas sociais.

Para o desenvolvimento do projeto, num primeiro momento, realizou-se uma oficina de criatividade, oferecida durante a programação do Encontro Comemorativo dos 30 Anos do NETI, realizado nos dias 20 e 21 de agosto de 2012 no Centro de Cultura e Eventos da UFSC. Buscou-se nessa oficina a integração dos participantes com a história e linha do tempo do NETI. Cada participante pode expressar, através de trabalhos artísticos, os seus sentimentos, opiniões e aspirações em relação ao passado, presente e futuro do núcleo.

Num segundo momento, foram promovidas visitas a diferentes espaços culturais e científicos da universidade, "[...] propiciando um refazer de espaços, uma construção do ser como habitante de seu próprio mundo, definindo novas trajetórias para seu estar-no-mundo" (STANO, 2001, p.163). Tais visitações 
possibilitaram aos participantes do projeto o contato com diferentes manifestações artístico-culturais e científicas, incluindo o contato intergeracional através da companhia de alunos do quarto ano de uma Escola Básica de Florianópolis.

\section{A Oficina de Criatividade}

O processo de criação é inerente à natureza humana, está presente em todas as etapas da vida, independente da idade ou da educação formal; porém, algumas vezes o criar pode ser neutralizado ou adormecido por diferentes circunstâncias do viver. Assim, faz-se necessário o estímulo constante para o desenvolvimento criativo, ressaltando que "[...] criatividade é importante nas relações interpessoais, desempenho e participação social, na busca espiritual, na educação e nas demais áreas da vida" (BARROS; BÚRIGO, 2003, p. 66). A oficina de criatividade teve como objetivo estimular a criatividade de seus participantes, permitindo-lhes mostrar, por meio de trabalhos realizados com tecidos, papéis e escritas, alguns de seus desafios e desejos para o futuro, relacionando-os ao NETI. Além disso, expressar o seu "estar" no NETI, para que, no final da atividade, pudessem ser integrados todos esses desafios individuais, formando um grande coletivo. Os participantes foram pessoas idosas presentes no Encontro Comemorativo dos 30 Anos do NETI, e contou-se com o apoio de voluntários do núcleo.

A oficina foi composta por quatro ilhas de atividades, que possibilitavam ao participante lidar com materiais distintos: a oficina de retalhos denominada "Colcha de retalhos"; a de colagem intitulada "Painel integrando sonhos"; a de escrita, "Expressões do desejo"; e ainda a de dobradura, "Jardim NETI - plantando ideias".

Algumas reuniões de planejamento foram realizadas para garantir a qualidade da execução das oficinas. Para isso, foram definidos o espaço necessário, o nome e frases motivadoras para cada ilha de atividades, os materiais a serem utilizados e a escolha da coordenação de cada ilha. Os materiais oferecidos na atividade foram revistas, papéis coloridos variados, tecidos, canetinhas, colas, tesouras, linhas e agulhas.

Para a "Colcha de retalhos", cada participante fez um trabalho individual com retalhos, ficando livre para criar e comunicar seus desafios futuros. A frase "Com seus retalhos, deixe suas aspirações” foi colocada próxima à ilha, estimulando o processo de reflexão e criação. Depois de pronto, os trabalhos individuais foram aplicados num tecido maior, ou seja, a grande colcha foi tecida coletivamente expondo a representação dos desafios futuros e nomeada por seus participantes como "NETI, onde mora o amor". Pode-se observar a vontade de cada participante em deixar na colcha a sua marca. As mais variadas formas de expressão foram registradas na colcha, tais como simples recortes de tecidos colados, tecidos trabalhados em diferentes formatos e ainda imagens impressas representativas de ações e sentimentos.

$\mathrm{Na}$ ilha de colagem, cada participante pode realizar a colagem de imagens de revistas para expor seus íntimos desafios para o seu futuro e do NETI. Os trabalhos foram inseridos num painel coletivo, visando à união de forças para buscar e realizar os desafios ali colocados. "Recortando e colando, vamos nos transformando..." foi a frase que inspirou os "artistas" do painel.

A oficina de escrita promoveu a livre expressão dos desejos de cada participante através do registro gráfico de alguns dos desafios pessoais e para o NETI. O tema “Expresse a essência de seus sonhos!" estimulou a participação, reflexão e exposição dos trabalhos em forma de varal. Observou-se que, além dos sonhos, também foram emitidos sentimentos de agradecimentos pela história construída ao logo da existência no NETI, parabenizando-o pelos seus 30 anos e ainda ressaltando a percepção das melhores características do núcleo.

A oficina de dobradura intitulada "Jardim NETI - plantando ideias" foi desenvolvida utilizando-se técnicas de dobraduras em papel, com a criação de uma flor, a qual foi "plantada no jardim”. Solicitou-se a cada participante que registrasse no caule da flor "o que foi o NETI para mim" e nas pétalas "quais oportunidades gostaria de encontrar futuramente no NETI". Todos os desafios descritos nessa ilha compuseram um lindo e 


\section{Extensio $\mid$ Relato de Experiência}

colorido jardim de ideias e oportunidades.

Os trabalhos resultantes das oficinas foram apresentados ao público no encerramento do Encontro Comemorativo dos 30 Anos do NETI, em forma de painel, com o objetivo de mostrar a expressão criativa dos participantes, divulgar a manifestação proativa e reflexiva da pessoa idosa inserida no contexto da educação para o envelhecimento, bem como a declaração da construção coletiva dos anseios futuros.

\section{As visitas aos espaços culturais e científicos da UFSC}

Segundo Freire (1999), a construção e a produção do conhecimento do objeto implicam o exercício da curiosidade, sua capacidade crítica de observá-lo, delimitá-lo. A visitação de determinados espaços do campus universitário, ainda pouco explorados, visou instigar os participantes do projeto à curiosidade, ao conhecimento do novo, estimulando sua capacidade de aprendizagem e a convivência intergeracional, com vista à valorização, integração e bem-estar dos alunos do NETI na universidade.

O projeto promoveu diversas visitas e atividades, explorando diferentes ambientes físicos e culturais da UFSC. Segundo Portella (2004, p. 101), “[...] para o idoso, construir a cidadania passa por um processo de libertação, como uma excursão para lugares ainda não explorados [...]”. Foram realizadas as seguintes visitas: Museu de Arqueologia e Etologia Oswaldo Rodrigues Cabral; Planetário e Parque Viva Ciência; Teatro da UFSC com a apresentação do Grupo Teatral Chão de Estrelas e conversa com a escritora Ana Esther de Val, contando seu processo de criação da personagem "Mega Avó" e seus casos. O projeto contou com a participação de alunos, estagiários e professores de diferentes cursos do NETI, e colaboradores do Núcleo, bem como alunos de uma escola básica de Florianópolis.

A visitação ao Museu de Arqueologia e Etologia Oswaldo Rodrigues Cabral da UFSC foi realizada numa tarde de outubro de 2012, e os alunos contemplaram a exposição "Povo Tucunas", o importante acervo de arqueologia pré-colonial e histórica, e o acervo de etnologia indígena. A exposição das lindas obras de arte de Franklin Joaquim Cascaes - desenhos, manuscritos e esculturas que retratam o cotidiano, a religiosidade, lendas, mitos, folguedos folclóricos e tradições dos primeiros colonizadores da Ilha de Santa Catarina - proporcionou aos alunos viajar no mundo das artes, fazendo um levantamento da cultura indígena e açoriana, e ainda conhecer sobre a metodologia de estudos antropológicos, descrita por Silvio Coelho. O conhecimento e ocupação do espaço motivaram os alunos idosos para a realização de trabalhos extraclasse, como a escrita de poemas e confecção de cartazes, os quais foram expostos no núcleo.

A visita ao Planetário e ao Parque Viva Ciência da UFSC, realizada numa manhã de outubro de 2012, estimulou o idoso para novas descobertas, instigando-o a conhecer um pouco sobre o mundo mágico dos céus, da ciência astronômica e da física. Nessa atividade, a convivência intergeracional de alunos idosos foi promovida com a inclusão de crianças da escola básica, favorecendo a ação e reflexão para recriar o próprio espaço de aprendizado, para além do espaço concreto da escola, penetrando na seara da afetividade, ou seja, a formação de vínculos e cumplicidade para todas as idades (STANO, 2001).

Numa manhã de atividades artístico-culturais, a apresentação de uma peça teatral pelo Grupo Chão de Estrelas, denominada "O idoso e suas relações com o outro", foi oferecida aos alunos do NETI e alunos da escola básica no Teatro da UFSC, em novembro de 2012. Na continuidade das atividades desse dia, a escritora Ana Esther de Val relatou sua trajetória de criação literária, especialmente sobre a personagem "Mega Avó", uma heroína defensora dos idosos oprimidos. Tal relato atendeu ao objetivo de provocar manifestações e participação ativa dos presentes na discussão sobre o significado de envelhecer em nossa sociedade e as implicações políticas e sociais. Para essa manhã cultural, contou-se com a ajuda dos responsáveis pelo Grupo Teatral Chão de Estrelas: a autora Ana Esther de Val, a aluna Elna de Oliveira Silva, do Curso de Contadores de Histórias/NETI, além do empenho da Margarete Mello, aluna do Curso de Formação de Monitores de Ações Gerontológicas/NETI. Todos os voluntários participaram de forma espontânea e gratuita. 


\section{Resultados e análise}

O projeto "Ressignificando a arte do envelhecer" atendeu aos objetivos de integrar ações de cunho cultural entre as atividades oferecidas pelo NETI, através da reflexão e ressignificação dessas atividades no processo educativo, promovendo o desenvolvimento, valorização e potencialização do ser humano. O estímulo para o convívio entre alunos do NETI e o convívio intergeracional, através das oficinas e das visitas realizadas em diversos espaços da universidade, foram facilitadores de conteúdos socioeducativos. Os trabalhos em grupo possibilitaram a interação com o outro, estimulando o potencial criativo individual e coletivo, favorecendo o crescimento pessoal, incentivando a participação social ativa, promovendo a integração de diferentes manifestações artístico-culturais e sociais na comunidade, estimulando uma imagem construtiva do idoso.

$\mathrm{Na}$ oficina de criatividade, observou-se a importância do núcleo para o bem-estar, desenvolvimento e aprimoramento de seus alunos e colaboradores, favorecendo a inserção no meio social e educacional. Entre alguns dos relatos descritos no "Jardim", podem-se citar: "A importância do NETI é tudo. Começo de uma vida nova - renascimento", "Aprendi a importância da amizade e do respeito à individualidade de cada um", "O NETI é a possibilidade de um envelhecer com dignidade e cidadania".

Entre as expectativas dos alunos com relação ao futuro do NETI, os participantes deixaram registradas as seguintes mensagens: "que tenha cada vez mais cursos, para abrir mais portas", "mais integração em termos de lazer", "espaço maior para as atividades" e sugestões de novos cursos, como música, dança e artesanato.

A visita ao museu despertou o interesse de muitos alunos pela cultura e artes visuais, instigando-os a continuar pesquisando, analisando, comparando e avaliando, construindo um saber popular elaborado e crítico sobre arqueologia pré-colonial e etnologia indígena e ainda o conhecimento acerca de Franklin Cascaes e suas obras.

A experiência de contato direto com o mundo da física e da ciência na visita ao Planetário e ao Parque Viva Ciência possibilitou acessar novos conhecimentos, desencadeando outros sonhos e planos "[...] que se constrói com o outro, [...] num processo de construção de experiências e significados compatíveis com o devir do homem, não como um fim e sim como meio para dar voz e vez aos que se sentem ávidos de vida com qualidade" (STANO, 2001, p.158).

A representação teatral e o bate-papo com a autora Ana Esther de Val foi um momento cujo destaque principal foi a intergeracionalidade. Discutiram-se concepções preconceituosas sobre o envelhecer, semeando ideias para mudança de atitudes em relação à velhice, valorizando as experiências que a pessoa idosa carrega consigo. A atividade auxiliou os alunos de todas as idades em prol do processo de envelhecimento saudável, articulando a integração e troca de experiências entre crianças e idosos, "[...] promovendo uma ampla conscientização, priorizando políticas de reeducação social em relação à pessoa idosa” (LIMA, 2008, p.31).

Em outras palavras, o projeto vem reforçando as relações das pessoas com o outro e com o mundo, como oportunidade de ressignificação da autoimagem e da autoestima. Segundo Buriti (2006), tais atividades incentivam a sociabilidade e a comunicabilidade, expandindo o universo cognitivo mediante novas experiências vivenciais. Verifica-se que a atividade em grupo com as pessoas idosas favorece o acesso e contato com suas próprias histórias e do outro, conhecimentos, experiências e identificação de necessidades, como um recurso para estimular a memória, comunicação e criatividade, além do exercício do protagonismo.

Em suma, as atividades socioeducativas desse projeto estimularam a pessoa idosa a ser protagonista de suas ações, promovendo seu autoconhecimento e crescimento pessoal, com vista à melhoria da sua qualidade de vida, pois toda experiência vivida, conteúdo apreendido e vínculos estabelecidos estimularam o ser e agir no mundo. Educar é um ato humano por excelência, em que a intenção se faz presente e a ação se desencadeia diante do desejado, do imaginado (STANO, 2001). Assim, mediar ações favoráveis à construção de seres que dão significado às suas próprias histórias e buscam a cada dia uma nova aprendizagem resultou no trabalho que requer a continuidade, para que os alunos possam expressar seus desejos e anseios de forma mais efetiva, permitindo-lhes usufruir as mais diferentes formas de expressões e de participação ativa e 


\section{Extensio | Relato de Experiência}

criativa, para que possam viver a longevidade plenamente.

\section{Considerações finais}

O projeto "Ressignificando a arte do envelhecer" promoveu a vivência de experiências artísticoculturais significantes para a reflexão do conhecer, fazer, conviver e crescer como protagonistas do próprio processo de envelhecimento. Foram oferecidas oficinas de criatividade e visitas em diferentes espaços da UFSC, possibilitando a integração dos participantes na construção de um novo significado à convivência pessoal e institucional, enquanto alunos do NETI e cidadãos brasileiros. Constata-se a necessidade de (re) inventar os espaços de convivência e de educação permanente, com o incentivo sempre presente para a participação ativa da pessoa idosa no meio universitário e comunitário, de modo interativo e intergeracional, com vista ao envelhecer saudável e, sobretudo, com sentimento de autorrealização pessoal, independente da idade.

\section{REFERÊNCIAS}

ANDER-EGG, E. Metodología y Práctica de la animación Sociocultural. Editorial CCS, Madrid, 2000.

BARROS, Monize Ferreira Amorin; BÚRIGO, Silvana. O espaço das oficinas pedagógicas no exercício da criatividade e educação permanente na velhice. Monografia ao Curso de especialização em gerontologia - NETI, 2003. 81p.

BURITI, Marcelo de Almeida. Lazer e Envelhecimento. In:WINTTER, Geraldina Porto (Org.). Envelhecimento: referenciais teóricos e pesquisa. Campinas, SP: Editora Alínea, 2006.

ESTHER, Ana. Mega avó - nasce uma heroína. Disponível em: http://www.recantodasletras.com.br/ cronicas/1190692. Acesso em 21 março de 2013.

FREIRE, Paulo.Pedagogia da autonomia: Saberes necessários à prática educativa. 11ed. Ed. Paz e Terra, SP. 1999.

IBGE, Instituto Brasileiro de Geografia e Estatística. Censo Demográfico de 2010. Disponível em: http:// www.ibge.gov.br/censo2010. Acesso em 21 março de 2013.

LIMA, Cristina Rodrigues. Programas intergeracionais:um estudo sobre as atividades que aproximam as diversas gerações.Ed. Alínea, Campinas, SP. Coleção velhice e sociedade. 2008.200p.

PORTELA, Marilene Rodrigues. Grupo de terceira idade: a construção da utopia do envelhecer saudável. Passo Fundo: UPF, 2004. 176p.

STANO, Rita de Cássia M. Trindade. Espaço escolar: um tempo de ser-na-velhice, 2001.In:

KACHAR, Vitória (Org.). Longevidade - um novo desafio para a educação. São Paulo: Cortez, 2001. 